\title{
Developing networks between residential aged care facilities as a result of engagement in a falls prevention project: an action research study
}

\section{Authors}

Emma Lea, $\mathrm{PhD},{ }^{1}$ Sharon Andrews, $\mathrm{PhD}, \mathrm{RN},{ }^{1}$ Terry Haines, $\mathrm{PhD},{ }^{2}$ Jennifer Nitz,

$\mathrm{PhD}, \mathrm{FACP},{ }^{3}$ Betty Haralambous, MSW, ${ }^{4}$ Kirsten Moore, $\mathrm{PhD},{ }^{5}$ Keith Hill, $\mathrm{PhD}$, MAPA, FAAG, ${ }^{6}$ Andrew Robinson, $\mathrm{PhD}, \mathrm{RN}^{1}$

1 School of Health Sciences and Wicking Dementia Research and Education Centre, University of Tasmania, Australia

2 Monash University and Allied Health Clinical Research Unit, Southern Health, Victoria, Australia

3 School of Health and Rehabilitation Sciences, University of Queensland,

Queensland, Australia

4 National Ageing Research Institute, Parkville, Victoria, Australia

5 Marie Curie Palliative Care Research Department, University College London, London, UK.

6 School of Physiotherapy and Exercise Science, Curtin University, Perth, Western Australia, Australia

\section{Corresponding author:}

Andrew Robinson, School of Health Sciences and Wicking Dementia Research and Education Centre, University of Tasmania, Private Bag 143, Hobart TAS 7001, Australia.

Email: Andrew.Robinson@utas.edu.au

Ph: +61 (0)3 62264735 


\section{Acknowledgements:}

The Australian Government Department of Health and Ageing (Canberra) provided financial support for this research as part of the "Encouraging Best Practice in Residential Aged Care" program. The funding source had no involvement in study design, collection, analysis or interpretation of data, in the writing of this paper, or the decision to submit the paper for publication. We thank Brendan Churchill for assistance with data collection and the staff of the residential aged care facilities involved with this project. 


\begin{abstract}
Background: Residential aged care facility staff often operate in isolation. Research is lacking on networking between facilities.

Aims: To explore outcomes associated with network formation between two residential aged care facilities as part of an action research approach to reducing falls. Design: Action research approach with qualitative data collected.

Methods: Twelve residential aged care facility staff from two facilities in regional X, Australia, formed a falls prevention action research group. Thematic analysis was undertaken of 22 audio-recorded fortnightly group meetings.

Results: This was the first opportunity for participants to meet colleagues from another facility in a professional context. The formation of an inter-facility network enabled the sharing of ideas and systems related to evidence-based falls prevention activities and other issues and galvanised a collaborative focus for action.

Conclusions: An action research process can be used to create an inter-facility network. Such networks can decrease staff isolation and facilitate best resident care. Keywords: accidental falls; community networks; evidence-based practice; health services research; nursing; residential aged care facilities; action research
\end{abstract}




\section{Introduction}

As the world population ages (United Nations, 2013), health care services including nursing homes [referred to hereafter by the Australian term 'residential aged care facilities' (RACFs)] are facing pressure to provide care for increasingly dependent resident populations (Australian Institute of Health and Welfare, 2012; Boyd et al., 2011; Onder et al., 2012). An important consideration in dealing effectively with this demand is to promote the implementation of evidence-based best practice in RACFs to improve the quality of care provision, as has been reported in Canada (Kaasalainen et al., 2010), Australia (Masso \& McCarthy, 2009) and the US (Rahman, Applebaum, Schnelle \& Simmons, 2012), to improve the quality of care provision (Kaasalainen et al., 2010; Masso \& MeCarthy, 2009). The formation of networks within the health care system is increasingly being recognised world-wide as a means to facilitate the development of capacity to implement evidence-based practices (Cunningham et al., 2012; French et al., 2009; Ghosh \& Marquard, 2007). Networks act as "mediating structures" (Walker, 1992: 262) to link people, agencies and services (Robinson, 2001). Relationships in networks are characterised by reciprocity (Powell, 1990) and the pursuit of "common or mutually beneficial goals or interests" (Oliver, 1990: 244). The benefits of networks centre on social capital (relationships) and intellectual capital (knowledge) (Fenton, Harvey, Griffiths, Wild \& Sturt, 2001). Social capital can facilitate the dispersal of information throughout the network and enables cooperative behaviour, while intellectual capital is created through collaboration and exchange amongst network members, particularly when members can contribute different resources (Powell, 1990).

Studies from the UK, USA and Australia have reported that RACF staff often operate in isolation (Robinson et al., 2005; Venturato, Kellett \& Windsor, 2006; 
Hasson, Kernohan, Waldron, Whittaker \& McLaughlin, 2008). RACF staff in these

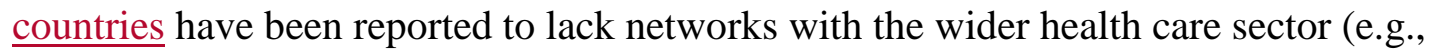
acute care, specialist services) and with the higher education sector (Hasson et al., 2008; McConnell, Lekan \& Corazzini, 2010; Robinson et al., 2005; Robinson \& Horner, 2014; Venturato et al., 2006). Contributing to this lack of networking between RACF staff and the wider health care and higher education sectors is the reported professional disengagement of facility staff (Hasson et al., 2008; Toles \& Anderson, 2011; Venturato et al., 2006). The absence of networks between professionals and between RACFs and the wider health/education sectors undermines opportunities to build skills and knowledge and has adverse ramifications for the development of evidence-based practice in RACFs (Furaker \& Agneta, 2013; Hasson et al., 2008; Kaasalainen et al., 2010; Venturato et al., 2006).

Although there is a recognition that more collaborative approaches need to be adopted across the residential aged care sector (Maly et al., 2012), little is known internationally about the degree to which RACFs network with each other and how the development of inter-facility networks might facilitate professional engagement. A previous Australian study identified that RACF staff were isolated from staff from other facilities and that networking between facilities increased motivation of nursing staff and provided an impetus for professional development (Robinson et al., 2005). Nursing staff from different facilities were able to compare issues and collaborate to take action to promote best practice. In addition, networking provided an opportunity to decrease financial demands by pooling resources to develop a collaborative professional development in-service program (Robinson et al., 2005). Given the potential benefits of networking between RACFs, there is scope for building on the existing research. The networking literature suggests that networks are more likely to 
form between homogenous groups, as trust levels are higher, suggesting that formation of networks between RACFs could be successful (Powell, 1990).

For the study reported on in this paper, the development of best practice falls prevention strategies in RACFs using an action research approach served as a framework for describing the development and impact of inter-facility networking, including on staff capacity to adopt evidence-based practice via knowledge development and increased engagement around falls prevention. Falls are a key issue in RACFs world-wide, occurring at about three times the rate of falls in the community, and resulting in considerable cost, as found by another part of this project [\$AU1887/\$US1792 per person with a 2008 base year (Authors, 2013)], morbidity and mortality (Cameron et al., 2012; Nurmi \& Luthje, 2002). Action research is a research approach with an emphasis on collaboration between participants, a focus on local problems, and an orientation towards action, knowledge development and improvement (Kemmis \& McTaggart 1986; Montoya \& Kent 2011; Reason \& Bradbury, 2001). Action research approaches to promoting evidence-based practice in RACFs have been shown to facilitate staff engagement and change in the practice of resident care by providing opportunities for staff discussion and encouraging participation of staff in the identification of issues and in actions (Andrews, McInerney \&Robinson, 2009; Authors 2012a; Authors 2012b; Phillips, Davidson, Jackson \& Kristjanson, 2008). In this way, action research approaches provide an impetus for network formation between facility staff and across facilities, which may not only have implications for the isolation of staff working within these facilities but for implementation of falls prevention practices. 


\section{Methods}

Aims

This paper reports on one component of a multi-faceted project called the Star project, described fully in the project protocol (Authors, 2010). The Star project involved the development of eight 'Falls Action Research Groups' (described below) comprising staff from RACFs across three Australian states (two in Tasmania, five in Victoria, two in Queensland) and intended to support effective implementation of evidence-based falls prevention activities. Seven of these eight Falls Action Research Groups were each undertaken in only one RACF, with only one group involving two different RACFs - the Tasmanian Falls Action Research Group. This paper focuses on the Tasmanian Falls Action Research Group, specifically the unique network which emerged between the two RACFs as a critical part of implementation of the action research approach to falls prevention. The aims are to describe (1) how the network was formed between the two RACFs, including barriers and facilitators of its development, (2) how the network was operationalised, and (3) whether there were any outcomes of development of this network for staff participation in falls prevention practices.

\section{Design}

An action research approach was employed during 12 months of field work in RACFs participating in the Star project. This approach aimed to facilitate the engagement of RACF staff in a systematic investigation of their practice to bring about improvement in falls prevention practices. Action research is a useful method when people, such as aged care staff, want to better understand and improve their practice (Kemmis, 2007; Street \& Robinson, 1995). A cornerstone of implementing an action research project is the establishment of an action research group where 
people can work together and take action on specific issues (Kemmis \& McTaggart, 1986). Most participating facilities in the Star project operated their action research processes within their own facility. However, the two Tasmanian facilities opted to conduct their action research process together, following discussion between the Tasmanian project lead (XX) and the respective facility managers. Therefore, for this study, a Falls Action Research Group consisting of volunteer staff members was established across the two Tasmanian RACFs that participated in the Star project (demographic and role details of group members are provided in the 'Participants' section below).

A number of action research scholars have highlighted the importance of assisting "co-researchers" to develop understanding of the action research process and their roles within it (Reason \& Bradbury, 2001; Waterman, Harker, MacDonald, McLaughlin \& Waterman, 2005). Therefore, the Falls Action Research Group was presented with education and resources about action research and was supported in its implementation by project team members experienced in using action research methods in RACFs. Under the guidance of a project officer, the group proceeded through a recurring spiral of steps that involved preliminary investigation and problem identification, problem solving, planning, taking action and collecting data, analysis and reflection, and replanning (see Figure 1), consistent with Kemmis and McTaggart (1986). The data for this paper arise from analysis of discussions that occurred during a series of the group's meetings held over the course of the project. 


\section{Participants}

The two RACFs were located in a regional Tasmanian city within $10 \mathrm{~km}$ of each other, with one being charitable and the other privately funded. Each RACF had 100-150 beds, consisting of both high and low care, and 150-200 staff members, including casual and part-time. There are two factors that possibly played a role in the willingness of staff from these two facilities to meet as a single group rather than independently in their own facility. First, a precedent had been set for facility involvement with research activities; both RACFs had been involved in a previous productive University of $X$ research project (Authors, 2005). This prompted the two RACF managers to negotiate to work together for the current project, although none of the staff involved in the Falls Action Research Group had experience with the previous research project (Authors, 2005). Second, because the facilities were proximally located, meetings between them were considered feasible.

For the Star project, each facility was allocated funding to release a nursing staff member who volunteered to take the role of key contact and project support person, known as the falls resource nurse (0.2 full-time equivalent). The two Tasmanian falls resource nurses (FRNs) helped form, and became members of, the Tasmanian Falls Action Research Group. Any staff members that shared an interest in falls prevention were recruited into this group. Meetings were held on a day and time best suited to facilitate attendance (i.e. during a change-over in shift) and facility management was supportive, as indicated by their provision of backfill for staff when necessary. A high level of engagement with the project was exemplified by some staff attending meetings on days they were not at work. A total of 12 staff members, six from each facility, volunteered to form one group. Eleven of the twelve group members were female and seven were aged between 46 and 55 years. Members 
consisted of registered nurses (RNs; $n=3)$, enrolled nurses $(n=3)$, domestic and maintenance services staff $(n=3)$, care assistants $(n=1)$, physiotherapy assistants $(n=1)$ and lifestyle and leisure assistants $(\mathrm{n}=1)$.

\section{Data Collection and Analysis}

The Falls Action Research Group members met fortnightly for a year from May 2008, totaling 22 meetings, with a high attendance rate of $84 \%$. A project officer external to the facilities who had been trained by an experienced action research facilitator ran the meetings. A "reconnaissance" or preliminary investigation (Kemmis \& McTaggart, 1986) formed the first nine group meetings and included a demographic survey (members' gender, age, occupation). A list of topics compiled by the project team guided these preliminary, semi-structured discussions (e.g., knowledge of best practice guidelines, issues that impact upon or facilitate falls management, previous opportunities for staff to discuss practice issues). The discussions, together with baseline quantitative data for their respective facilities (gathered to assess how well facilities were implementing evidence-based falls prevention practices, see Authors, 2010), enabled problems with falls-related practices in the facilities to be identified by group members. Afterwards, group members planned and implemented actions to address evidence-based gaps in their practices over the course of two action cycles, during or concurrent with the remaining 13 meetings.

The meetings were audio-recorded and transcribed verbatim. NVivo QSR Version 8 software was used to assist with qualitative data management. Two research team members independently analysed the transcripts and regularly met to explore the results. The transcripts underwent thematic analysis (Hansen, 2006) with data being coded according to emergent themes. Themes around inter-facility 
networking are reported in this paper (other aspects of the action research components of the project are reported elsewhere, namely Authors (2012a) on falls risk assessment processes and Authors (2012b) on increased collaboration between staff from different occupational groups).

\section{Ethical Considerations}

The X Ethics Committee (Ethics Ref. H9907) approved the project. Staff members wishing to join the Falls Action Research Group were provided with a Plain Language Statement inviting their participation in the study and signed a Consent Form.

\section{Rigour}

The soundness of the research was tested by the criteria of credibility, dependability, confirmability and transferability (Lincoln \& Guba, 1985). Credibility was improved by the project officer developing the meeting transcripts into minutes and returning them to group members before the next meeting. This facilitated Falls Action Research Group members' reflection on emerging issues, enabled the project officer to 'test' emerging themes with group members to ensure they reflected their experiences, and enabled member checking. Validating the described experiences with the reported findings leads to dependability of the findings. Credibility was also enhanced by the project officer discussing the data and emergent themes with a group of project team members with extensive qualitative research experience and/or clinical expertise in residential care. Confirmability requires the researcher to accurately and clearly record the evidence and thought processes which led to the conclusions. Data were checked and rechecked independently by two research team members, who met to explore common themes and different explanations, while another researcher took a 'devil's advocate' role with regard to interpretation of the 
findings. In terms of transferability, it is the responsibility of the user of the findings to make a judgement on applicability to their particular situation (Lincoln \& Guba, 1985).

\section{Findings}

\section{First Opportunity to Meet in a Professional Context}

The Falls Action Research Group members had not previously met with colleagues from their own facility to explore their practice, let alone with colleagues from another RACF. The Star project provided the first opportunity for this to happen in a professional context when the group members from two RACFs met together fortnightly. Members reported knowing little about the other facility involved with the project prior to project commencement. As one member stated:

I knew nothing about [the other facility] other than [a relative] worked there.

That's about all I knew. [RN]

\section{Creation of an Inter-facility Network - Facilitators and Barriers}

The opportunity provided by the project for staff from two facilities to meet enabled the creation of a network between the RACFs. The process began with group members sharing stories of their practice and their perceptions of what the key falls prevention issues were in their facilities. This process was facilitated by a project officer, since group members were unfamiliar with participation in research, aside from the limited training they had received (as outlined in Design). Not surprisingly, given their role as the clinical leaders in the RACFs, it was the RN members of the group who led much of the discussion.

Group members were enthusiastic about the opportunity presented by the project to meet staff from another RACF. Early on in the project they outlined some 
benefits associated with working with staff from another facility. In particular, participants thought that collaboration with other facilities (putting "more heads together") would be a useful process that would allow ideas to be shared:

I'd always thought that it would be so helpful to work with another facility...to get together and share ideas. [RN]

However, it was noted that the opportunities to collaborate simply did not occur in residential aged care, with participants commenting that "I don't think there's enough sharing of ideas between facilities" and "It's surprising that there's not more of it [happening].” Participants recounted that this desire to hold inter-facility meetings was widespread and longstanding:

Whenever I've gone to conferences and talk to nurses or managers from other nursing homes, they all say the same thing - that they'd love to be able to get together and discuss some things. [RN]

According to group members, one reason why inter-facility networking is not more commonplace is a sense of mistrust and rivalry between facilities, which functions as a barrier to collaboration. For example, one participant relayed that "there are a lot of facilities that are quite competitive with other facilities, they don't share ideas." Participants noted that it was important "not [to] see them [other RACFs] as the enemy" but instead as useful resources. Participants recognised that despite there being some differences between the two RACFs, such as how they are funded, there were many similarities, including similar issues with respect to falls prevention. This realisation broke down potential barriers to the sharing of ideas and working together. It also galvanised a commonality of purpose. As one staff member stated: 
I think there is a lot of comparable stuff ... [The FRNs] have great respect for the staff and have a love of aged care and the residents... So we're working from the same sort of base. We've ... got the same sort of infrastructure. [RN] Importantly, it was recognised that the facilities shared core objectives, with each organisation "trying to achieve the same thing, just coming from different angles." Thus, the participants' perception of the benefits of meeting together, particularly the sharing of ideas regarding falls prevention, together with their ability to sense a common purpose between the facilities, formed the basis for a network.

\section{Operationalisation of the Network - Sharing Information and Resources and}

\section{Building Inter-facility Relationships}

During the meetings, information exchange occurred between the facilities as a result simply of meeting together, even prior to planning and conducting the action research activities to address evidence-based gaps in their practice. Sharing ideas was considered a key benefit of meeting with staff from other facilities, as typified by one member:

It's been fantastic for people...to be able to tap into another facility's personnel and share ideas. [RN]

Group members obtained ideas from the other facility about ways to help prevent falls, such as improved documentation and a system for recognising residents at high risk of falling. In addition to sharing ideas about falls prevention practices, group members "shared ideas on all sorts of things", such as staffing, documentation, manual handling training and diversional therapy programs. One member relayed how staff from her facility were planning to visit the other facility to learn more about their diversional therapy program, as she said, "because ours could do with some improving”. One RN commented that the meetings created an opportunity to: 
"... pick those areas that we all have difficulties with and then share ideas [about] systems that work to make things easier...[Meeting together means] we can share the easiest, quickest, most efficient way to do things [RN] In this way, participation by group members in the action research process was perceived to facilitate improvements in efficiency and effectiveness, which helped to compensate for what some members thought to be the largest issue with their participation in the research project, time restraints: "time has been the biggest hurdle for both facilities".

One factor that further assisted in the efficiency gains associated with the local network was the informal communication and relationship that developed between the FRNs. In addition to participation in the group meetings, the FRNs communicated outside the meetings in order to draw on each other's knowledge and experience to develop their respective programs. For example, via email they "tap[ped] into [each other's] resources and bounce[d] ideas." One of the FRNs explained the importance of having an opportunity to share ideas with her colleague as follows:

We know how much each other is struggling with time, resources: trying to find something that's quick, easy and efficient... What works, what doesn't and it [sharing ideas/experiences] just makes it so much easier. You don't have to worry about 'Is this going to work? Is it not going to work?' [RN] Through the project, the FRNs also received funding to attend a national falls conference for the first time. Being exposed to a range of research and professional colleagues at the conference inspired them to initiate greater sharing of resources. For example, pooling resources subsequently enabled both facilities to offer interventions such as tai chi classes to residents, an activity which has the potential to lower falls risk factors for residentsolder adults, although more research is needed to establish its 
effectiveness in the residential aged care setting (Dechamps et al., 2010Cameron et al., 2012; Li et al., 2005; Tousignant et al., 2013). Furthermore, attending the falls conference together helped the FRNs to strengthen their relationship, which worked to support the sustainability of the network. One group member noted that because the FRNs had "such a good rapport and complemented each other...it was easier for all of us: there was a ripple effect."

\section{Outcomes of Networking - Recognising Evidence-based Gaps in Falls Prevention}

\section{Practice}

Building a network between group members facilitated professional engagement, which in turn galvanised the plan to take strategic action. In conjunction with the project officer, mMembers examined baseline data collected from both facilities by the research team and identified evidence-based gaps in their practice. Lack of staff education was identified as a "big part of" the falls problem, with no staff training on falls or falls injury prevention occurring in either facility in the past year. It was noted that education was needed for all staff, not just nursing staff. One group member, from domestic services, stated that there was a lack of "education of the kitchen staff not parking their trolley in the middle of the hallway and the cleaning lady not parking hers right in front of the nurses' drug trolley." The imperative to have "more knowledge" about falls prevention emerged from the group's collaboration as an area for future action and a strategy to address evidence-based gaps in their practice.

Another issue that the group members identified through their collaborative examination of baseline data from their respective facilities as a significant falls risk was inappropriate footwear worn by residents. For example, one enrolled nurse member explained: 
A lot of the residents tend to wear slippers or slip-on shoes...you see them scuffing along...Footwear is a big issue... and I don't think we alert the families to footwear here. [EN]

Through their discussion the group members identified that best practice was not currently implemented with respect to podiatry consultations for residents. For example, at one facility residents had at best episodic access to podiatry reviews. One member, a care assistant, stated how at her facility there were a number of residents who "desperately need [shoe] fittings" conducted by a podiatrist.

From their discussion, the group members planned two strategic actions which aimed to address problems with residents wearing unsuitable shoes and the need for staff education about falls risks and prevention activities. The first action was a 'Shoe Day', wherein staff, residents and their families at both facilities were provided with information and education about the importance of residents wearing suitable footwear as a key strategy to lower falls risk. The second action was a 'Falls Awareness Week', which centred on facility-wide falls prevention training with an experiential focus for staff at each facility, as well as information sessions for residents and family members.

A key outcome of the group members having developed a network was that they benefited from being able to 'brainstorm' ideas and share information to develop evidence-based action plans. Moreover, on their own initiative, members from both facilities met on a number of occasions, without the project officer, to strategically plan these activities. During these collaborations members interrogated their proposed plans of actions to determine their feasibility and implementation strategies. These independent meetings demonstrated the growing autonomy and high motivation of the network members. 
Reflecting on the development of the network, group members emphasised that their facilities "changed quite a bit" and "improved" over the course of the project. They largely attributed this change to the relationships that had been formed between staff at the two RACFs and the multitude of opportunities that this had presented for learning and sharing ideas not only in relation to falls prevention, but a range of issues common to the RACFs. Hence, all of the members were keen to ensure that this network would continue after the project ended. As one member stated:

We've established a network here and it would be very sad if we don't continue the network going. $[\mathrm{RN}]$

\section{Discussion}

This paper presents some novel and positive findings associated with two independent residential aged care facilities coming together to form a network to utilise an action research approach in a broader falls prevention project, rather than working in isolation. It is important to note that for the remaining seven facilities participating in the Star project, with most with at least two facilities in the one city, no other facilities chose to consider the option of joining together for the action research component of their involvement. Key themes identified that reinforced the positive elements of the approach included looking for opportunities for collaboration; sharing and pooling of ideas, resources and activities; relationship building ${ }_{2}$ (including developing trust); and the potential to influence practice more broadly than the current falls prevention area of focus-(in this case-falls prevention).

This study found that staff from two X RACFs had little or no engagement with colleagues from other aged care facilities prior to project commencement. 
Indeed, this project provided the first opportunity for these staff to meet colleagues from another facility in a professional context; a process which led to the formation of an inter-facility network. This network enabled the sharing of ideas and systems between facilities related to falls prevention and a range of other issues and, in the context of an action research project, galvanised a collaborative focus for action. Although time restraints were identified as a key barrier to research participation by some group members, it was felt that this sharing across facilities assisted efficiency of practices and systems. Establishing knowledge networks is an important way of sharing evidence-based practices (Ghosh \& Marquard, 2007). This was evident in this project with staff from both facilities working together to plan and implement falls prevention activities, such as staff education and improved resident footwear, both of which are important to falls prevention (Büchele et al., 2014; Phillips, Yarmo Roberts \& Hunsaker, 2008; Vu, Weintraubd \& Rubenstein, 2006). Afndeed, $\underline{\text { though it should }}$ be noted that a stronger evidence base is needed for falls prevention interventions in the residential aged care setting (Cameron et al., 2012), these activities, in conjunction with other components of this project [including an environmental audit, as reported by Authors (2011)], reduced the proportion of fallers across eight of the nine RACFs involved with the project (Authors, 2012c). Based on the findings of this project we argue that bringing staff from different RACFs together within an action research framework works to build staff capacity to develop a more evidence-based approach to practice. Such collaboration provided an impetus for professional engagement. In this way, inter-facility networking may help mitigate the sense of powerlessness and lack of control that staff have been found to experience in residential aged care (Jones et al., 2002). 
While the international literature discusses the isolation of RACFs from the wider health care sector (Hasson et al., 2008; McConnell et al., 2010; Robinson et al., 2005; Robinson \& Horner, 2014; Venturato et al., 2006), there is a dearth of research that highlights the isolation of RACF staff from other RACF staff. The study findings suggest future research needs to consider such isolation in the context of efforts to develop evidence-based practice in residential aged care. Additionally, our study shows that it is useful to provide networking opportunities for non-professional staff, such as care assistants and ancillary staff, in these projects. For example, care assistants, as the primary care providers (King et al., 2012), were key players in identifying a focus for action with respect to problems with residents' shoes, and worked with their professional colleagues to institute a cross-facility intervention, the 'Shoe Day'.

The importance of trust as a factor behind the successful formation of networks has been well documented in the networking literature (Carswell, Manning, Long \& Braithwaite, 2014; Fenton et al., 2001; Powell, 1990), as has the need for overcoming the issue of competition between organisations (Shortell et al., 2002). These factors were also found to be important in the formation of the inter-facility $\mathrm{X}$ network in this study. Group members were prepared to work together, despite recognising the sense of rivalry between the two facilities. Through the network this rivalry was transformed into a collaboration in which they acknowledged each other as useful resources and powerful allies. Developing trust and meaningful relationships was central to this change. This was most evident with the two FRNs who built a strong relationship, maintaining communication outside of the group meetings. The importance of personal relationships such as individual friendships and personal histories in the formation of networks has been reported in the literature (Larson, 
1992). In addition, increased opportunities for professional engagement, which emerged in the context of the group meetings, assists skill and knowledge expansion among professionals and the development of evidence-based practice in RACFs (Carswell et al., 2014; Hasson et al., 2008; Venturato et al., 2006).

While this paper presents findings not previously published with respect to developing falls prevention practices in RACFs, the study findings need to be considered within the context of a number of limitations. Although the best available evidence was used at the time of the study, that was included in best practice guidelines (e.g. Australian Commission on Safety and Quality in Health Care, 2009), the best available evidence around falls prevention practices in the residential aged care setting may not yet be sufficient (Cameron et al., 2012). In addition, dĐata were collected from a small sample of staff that comprised the Falls Action Research Group from two Tasmanian RACFs, possibly limiting generalisability of findings to other RACFs. While there were similarities in the issues raised by group members between the two facilities with our earlier work (Authors, 2005), further research is required to establish the transferability of the findings for network formation between other RACFs. Some additional factors may have influenced the decision to work together between these two facilities, including characteristics of the facilities and staff, the support of the external facilitator, and perhaps a previous successful collaborative experience. The potential benefits of networking between RACFs found in this study indicate the need for further, larger-scale research within the residential aged care sector, including the barriers that impede this process. It would also be useful to look at whether any networks that are formed in RACFs are sustainable over the long term. 


\section{Conclusion}

This study has shown that an action research process is a useful technique to initiate the creation of an inter-facility network in the context of a falls prevention project. The results suggest that building networks between RACFs can be an effective strategy in reducing their isolation by enabling the sharing of ideas and systems across facilities, fostering a belief among staff that improvement is possible, and providing a collaborative focus for action. The positive results obtained from utilising an action research approach to facilitate RACFs networking together suggest that further research would be useful among a wider group of facilities in a variety of geographic locations. In addition, government policies and programs that promote and facilitate networking between facilities would be beneficial. For example, the Australian Government has partially funded the establishment of a national virtual network between some of the facilities who have been part of a program to build teaching aged care facilities; ongoing funding for this type of project is necessary. Funding for new leadership roles in RACFs to drive innovation, networking and evidence-based practice while working in collaboration with, and being supported by, university staff, in an extension of the FRN role in this study, would also be a potential pathway to facilitate network formation. Such measures are important as decreasing the isolation of RACFs by building networks between them may facilitate evidence-based practice and assist with building capacity among staff, for which there is a documented need in RACFs across a number of countries. 


\section{References}

Andrews, S., McInerney, F., \& Robinson, A. (2009) Realizing a palliative approach to dementia care: Strategies to facilitate aged care staff engagement in evidencebased practice. International Psychogeriatrics, 21, S64-S68. doi:

$10.1017 / \mathrm{S} 1041610209008679$

Australian Commission on Safety and Quality in Health Care (2009) Preventing falls and harm from falls in older adults: Best practice guidelines for Australian residential aged care facilities. Sydney: ACSQHC

Australian Institute of Health and Welfare (2012)- Residential aged care in Australia 2010-2011: A statistical overview. Aged Care Statistics Series no. 36.

Canberra, AIHW.

Authors (2005).

Authors (2010).

Authors (2011).

Authors (2012a).

Authors (2012b).

Authors (2012c).

Authors (2013).

Boyd, M., Broad, J. B., Kerse, N., Foster, S., von Randow, M., Lay-Yee, R., Chelimo, C., Whitehead, N., \& Connolly, M.J. (2011) Twenty-year trends in dependency in residential aged care in Auckland, New Zealand: A descriptive study. Journal of the American Medical Directors Association, 12(7), 535540. doi: 10.1016/j.jamda.2011.01.014

Büchele, G., Becker, C., Cameron, I.D., König, H-H., Robinovitch, S. \& Rapp, K. (2014) Predictors of serious consequences of falls in residential aged care: 
analysis of more than 70,000 falls from residents of Bavarian nursing homes. Journal of the American Medical Directors Association, 15(8): 559-563. doi: 10.1016/j.jamda.2014.03.015

Cameron, I.D., Gillespie, L.D., Robertson, M.C., Murray, G.R., Hill, K.D., Cumming, R.G., \& Kerse, N. (2012) Interventions for preventing falls in older people in nursing care facilities and hospitals. Cochrane Database of Systematic Reviews, 12(Art.No: CD005465). doi: 10.1002/14651858.CD005465.pub3.

Carswell, P., Manning, B., Long, J. \& Braithwaite, J. (2014) Building clinical networks: a development evaluation framework. British Medical Journal Quality and Safety, 23, 422-427. doi: 10.1136/bmjqs-2103-002405

Cunningham, F.C., Ranmuthugala, G., Plumb, J., Georgiou, A., Westbrook, J.I. \& Braithwaite, J. (2012) Health professional networks as a vector for improving healthcare quality and safety: a systematic review. British Medical Journal Quality and Safety, 21, 239-249. doi: 10.1136/bmjqs-2011-000187.

Darton, R., Netten, A., \& Forder, J. (2003) The cost implications of the changing population and characteristics of care homes. International Journal of Geriatric Psychiatry, 18(3), 236-243. doi: 10.1002/gps.815

Dechamps, A., Diolez, P., Thiaudiere, E., Tulon, A., Onifade, C., Vuong, T.,... Bourdel-Marchasson, I. (2010) Effects of exercise programs to prevent decline in health related quality of life in highly deconditioned institutionalized elderly persens: A randomized controlled trial. Archives of Internal Medicine, $170(2), 162169$.

Fenton, E., Harvey, J., Griffiths, F., Wild, A., \& Sturt, J. (2001) Reflections from organization science on the development of primary health care research networks. Family Practice, 18(5), 540-544. doi: 10.1093/fampra/18.5.540 
French, B., Thomas, L.H., Baker, P., Burton, C.R., Pennington, L., \& Roddam, H. (2009) What can management theories offer evidence-based practice? A comparative analysis of measurement tools for organisational context. Implementation Science, 4, 28. doi: 10.1186/1748-5908-4-28.

Furaker, C., \& Agneta, N. (2013). Registered nurses' views on nursing competence at residential facilities. Leadership in Health Services, 26(2), 135-147.

Ghosh, T., \& Marquard, J. (2007) Development of Regional Health Information Organizations (RHIOs): Knowledge networks and collaboration. International Journal of Public Policy, 2(3/4), 298-315. doi: 10.1504/IJPP.2007.012909

Hansen, E. (2006) Successful Qualitative Health Research. Allen and Unwin, Crows Nest, NSW.

Hasson, F., Kernohan, W.G., Waldron, M., Whittaker, E., \& McLaughlin, D. (2008) The palliative care link nurse role in nursing homes: Barriers and facilitators. Journal of Advanced Nursing, 64(3), 233-242. doi: 10.1111/j.13652648.2008.04803.x

Jones, J., Cheek, J., \& Ballantyne, A. (2002) Providing residential care to older Australians: Issues for registered nurses. Contemporary Nurse, 12(3), 225234.

Kaasalainen, S., Williams, J., Hadjistavropoulos, T., Thorpe, L., Whiting, S., Neville, S., \& Tremeer, J. (2010) Creating bridges between researchers and long-term care homes to promote quality of life for residents. Qualitative Health Research, 20(12), 1689-1704. doi: 10.1177/1049732310377456

Kemmis, S. (2007) Action research as a practice - changing practice. In Spanish Collaborative Action Research Network (CARN) Conference. University of Valladolid. 
Kemmis, S., \& McTaggart, R. (1986) The Action Research Planner ( $3^{\text {rd }}$ ed.). Deakin University Press, Geelong, VIC.

King, D., Mavromaras, K., Wei, Z., He, B., Healy, J., Macaitis, K, ... Smith, L. (2012). The aged care workforce, 2012. Canberra, Australian Government Department of Health and Ageing.

Larson, A. (1992) Network dyads in entrepreneurial settings: A study of the governance of exchange relationships. Administrative Science Quarterly, 37(1), 76-104. doi: 10.2307/2393534

\section{Li, F., Harmer, P., Fisher, J., McAuley, E., Chaumeton, N., Eckstrom, E., \& Wilson,} N.L. (2005) Tai Chi and fall reductions in older adults: a randomized controlled trial. Journal of Gerontology, 60A(2), 187-194.

Lincoln, Y.S., \& Guba, E.G. (1985) Naturalistic Inquiry. Sage, Beverly Hills, CA. Maly, M.B., Lawrence, S., Jordan, M.K., Davies, W.J., Weiss, M.J., Deitrick, L., \& Salas-Lopez, D. (2012) Prioritizing partners across the continuum. Journal of the American Medical Directors Association, 13(9), 811-816. doi: 10.1016/j.jamda.2012.08.009

Masso, M., \& McCarthy, G. (2009) Literature review to identify factors that support implementation of evidence-based practice in residential aged care. International Journal of Evidence Based Healthcare, 7(2), 145-156. doi: 10.1111/j.1744-1609.2009.00132.x

McConnell, E.S., Lekan, D., \& Corazzini, K.N. (2010) Assuring the adequacy of staffing of long-term care, strengthening the caregiving workforce, and making long-term care a career destination of choice: from mission impossible to mission critical? North Carolina Medical Journal, 71(2), 153-157. 
Montoya, M. J., \& Kent, E. E. (2011) Dialogical action: moving from communitybased to community-driven participatory research. Qualitative Health Research, 21(7), 1000-1011. doi: 10.1177/1049732311403500

Nurmi, I., \& Luthje, P. (2002) Incidence and costs of falls and fall injuries among elderly in institutional care. Scandinavian Journal of Primary Health Care, 20(2), 118-122.

Oliver, C. (1990) Determinants of interorganizational relationships: Integration and future directions. Academy of Management Review, 15(2), 241-265. doi: $10.2307 / 258156$

Onder, G., Carpenter, I., Finne-Soveri, H., Gindin, J., Frijters, D., Henrard, J.C., Nikolaus, T., Topinkova, E., Tosato, M., Liperoti, R., Landi, F. \& Bernabei, R. for the SHELTER project (2012) Assessment of nursing home residents in Europe: the Services and Health for Elderly in Long TERm care (SHELTER) study. BMC Health Services Research, 12(5). doi: 10.1186/1472-6963-12-5

Phillips, J.L., Davidson, P.M., Jackson, D., \& Kristjanson, L.J. (2008) Multi-faceted palliative care intervention: Aged care nurses' and care assistants' perceptions and experiences. Journal of Advanced Nursing, 62(2), 216-227. doi: 10.1111/j.1365-2648.2008.04600.x

Phillips, V.L, Yarmo Roberts, D., \& Hunsaker, A.E. (2008) Certified nursing aides' and care assistants' views on falls: insight for creation and implementation of falls prevention programs. Journal of the American Medical Directors Association, 9(3), 168-172.

Powell, W.W. (1990) Neither market nor hierarchy: Network forms of organization. Research in Organizational Behavior, 12, 295-336. 
Rahman, A.N., Applebaum, R.A., Schnelle, J.F., \& Simmons, S.F. (2012) Translating research into practice in nursing homes: can we close the gap? The Gerontologist, 52(5), 597-606.

Reason, P., \& Bradbury, H. (eds.) (2001) The SAGE Handbook of Action Research: Participative Inquiry and Practice ( $1^{\text {st }}$ ed.). Sage, London, UK.

Robinson, A. (2001) At the interface: Developing inter-sectoral networks in aged care - an action research study. Unpublished PhD thesis. La Trobe University, Bundoora, VIC.

Robinson, A.L., Venter, L., Andrews, S., Cubit, K., Menzies, B., Jongeling, L., ... Mather, C. (2005). Building Connections in Aged Care: Developing Support Structures for Student Nurses on Placement in Residential Care - Final Report. Hobart, Tasmania, School of Nursing and Midwifery, University of Tasmania.

Robinson, A., \& Horner, B. (2014). New approach to old school. Aged Care Insite, June, 25-26.

Shortell, S.M., Zukoski, A.P., Alexander, J.A., Bazzoli, G.J., Conrad, D.A., HasnainWynia, R., ... Margolin, F.S. (2002) Evaluating partnerships for community health improvement: Tracking the footprints. Journal of Health Politics, Policy and Law, 27(1), 49-91. doi:10.1215/03616878-27-1-49

Street, A., \& Robinson, A. (1995) Advanced clinical roles: investigating dilemmas and changing practice through action research. Journal of Clinical Nursing, 4(6), 349-357. doi: 10.1111/j.1365-2702.1995.tb00036.x

Toles, M., \& Anderson, R.A. (2011) State of the science: Relationship-oriented management practices in nursing homes. Nursing Outlook, 59, 221-227. doi: 10.1016/j.outlook.2011.05.001 
Tousignant, M., Corriveau, H., Roy, P-M., Desrosiers, J., Dubac, N., \& Hébert, R. (2013) Efficacy of supervised Tai Chi exercises versus conventional physical therapy exercises in falls prevention for frail older adults: a randomized controlled trial. Disability and Rehabilitation, 35(17), 1429-1435. doi: $10.3109 / 09638288.2012 .737084$

United Nations, Department of Economic and Social Affairs, Population Division (2013)

World Population Ageing 2013. ST/ESA/SER.A/348. UN, New York.

Venturato, L., Kellett, U., \& Windsor, C. (2006) Searching for value: The influence of policy and reform on nurses' sense of value in long-term aged care in Australia. International Journal of Nursing Practice, 12(6), 326-333. doi: 10.1111/j.1440-172X.2006.00591.x

Vu, M.Q., Weintraub, N., \& Rubenstein, L.Z. (2006) Falls in the nursing home: are they preventable? Journal of the American Medical Directors Association, 5, S53-58, 52

Walker, R. (1992) Inter-organizational linkages as mediating structures in community health. Health Promotion International, 7(4), 257-264. doi: 10.1093/heapro/7.4.257

Waterman, H., Harker, R., MacDonald, H., McLaughlan, R., \& Waterman, C. (2005) Advancing ophthalmic nursing practice through action research. Journal of Advanced Nursing, 52(3), 281-290. doi: 10.1111/j.1365-2648.2005.03594.x 


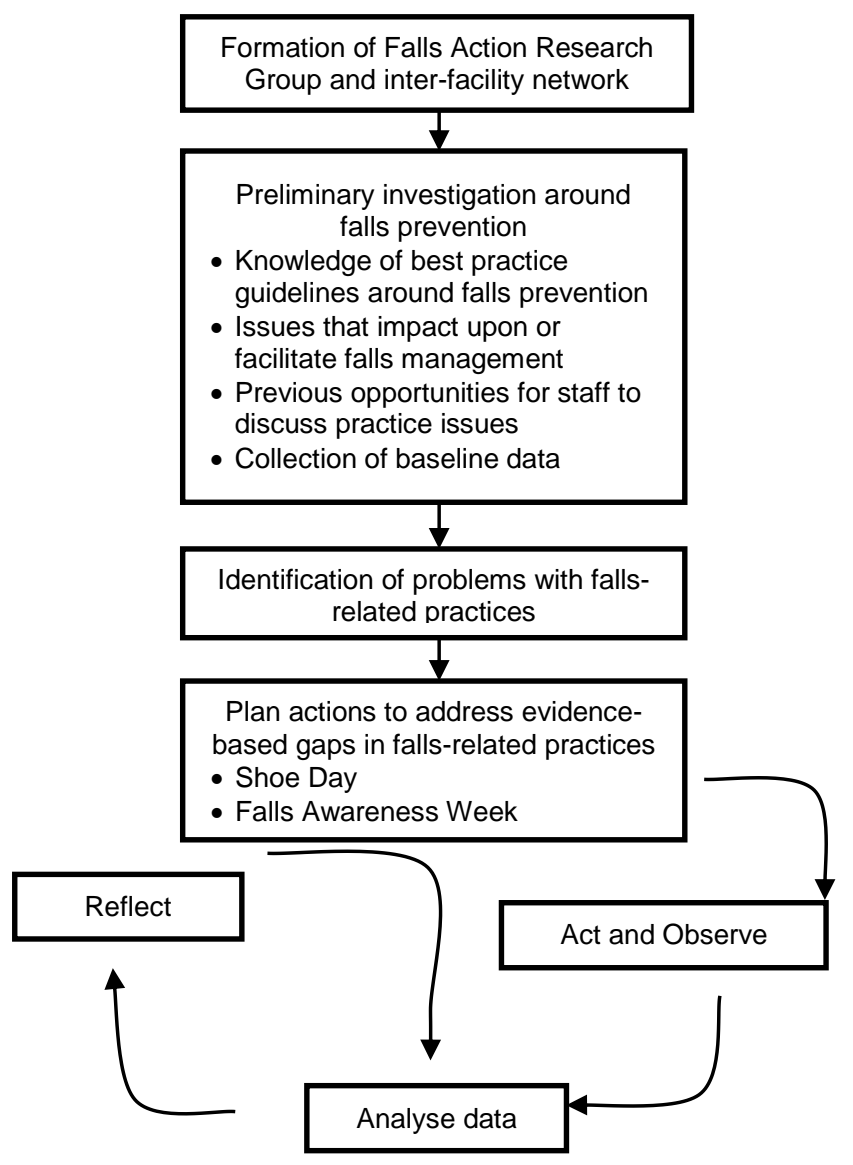

Figure 1: The action research process followed by the Falls Action Research Group (after Kemmis \& McTaggart, 1986) 